\title{
Iridium/Graphene Nanostructured Catalyst for the N-Alkyla- tion of Amines to Synthesize Nitrogen-containing Derivatives and Heterocyclic Compounds
}

\author{
Tsun-Ren Chen, ${ }^{*}$ Yu-Tung Chen, Yen-Hsing Lin, and Hao-Chen Wang \\ Department of Applied Chemistry, National Ping Tung University, Pingtong City, Taiwan \\ * Correspondence: $\underline{\operatorname{trchen} @ \text { mail.nptu.edu.tw }}$
}

\begin{abstract}
A facile iridium/graphene-catalyzed methodology providing an efficient synthetic route for C-N bond formation is reported. This catalyst can directly promote the formation of C-N bonds, without pre-activation steps, and without solvents, alkalis and other additives. This protocol provides a direct $\mathrm{N}$-alkylation of amines using a variety of primary and secondary alcohols with good selectivity and excellent yields. Charmingly, the use of diols resulted in intermolecular cyclization of amines, and such products are privileged structures in biologically active compounds. Two examples illustrate the advantages of this catalyst in organic synthesis: the tandem catalysis to synthesize hydroxyine, and the intermolecular cyclyzation to synthesize cyclizine. Water is the only byproduct, which makes this catalytic process sustainable and environmentally friendly.
\end{abstract}

Keywords: keyword Iridium; Graphene; Nanostructure; Heterogeneous; Heterocyclic

\section{Introduction}

Nitrogen-containing organic moieties are an essential structural unit, play a vital role in biologically active compounds, and are also of great significance in many fields of chemistry. The construction of the nitrogen-containing organic part is an important technology in synthetic organic chemistry, which is widely used in the synthesis of various medicines, agrochemicals, and fine chemicals.

Traditional synthetic routes for $\mathrm{C}-\mathrm{N}$ bond formation were the alkylation of amines with alkyl halides [1], which kinds of reactions were usually fast but with tremendous disadvantages, for example, overalkylation reducing the yield of the desired product, side reactions bringing about tedious purification procedures, the use of toxic reagents harmful to human health, and stoichiometric amounts of waste unfriendly to the environment.; therefore, many researches have been devoted to this topic, including hydroamination [2], Buchwald-Hartwig coupling [3], and Ullmann reactions [4]. Recently, a robust and sustainable method has been developed for this goal, which utilized a catalytic hydrogen autotransfer (HA) strategy to form a new $\mathrm{C}-\mathrm{N}$ bond by employing less toxic and more readily available alcohols as the alkylating agents [5]. This strategy has attracted great deal of attention because the sole byproduct in this process is water, offering a sustainable method with high atom efficiency. Until now, various catalysts have been discovered for the $\mathrm{N}$-alkylation of amines using alcohols as alkylating agents, in which most common catalysts were ruthenium [6] and iridium [7] complexes, but many other metals have also been explored [8]. Most of these studies reported the scope of substrate development, but some used complicated catalytic systems, unstable and non-reusable catalysts, and most of them must use bases, solvents and other additives, which confines the development of these proposals for a true green process.

\section{Experimental Section}




\subsection{Materials and Methods}

Iridium chloride ( $\mathrm{IrCl}_{3}$, anhydrous) was obtained from the Seedchem Co. Crystalline graphite was purchased from SHOWA Co. All other chemicals including ethanol were purchased from Acros and used as received. Aqueous solutions were prepared with double-distilled water from a Millipore system (>18 M $\Omega \mathrm{cm}$ ). For thin layer chromatography (TLC), silica aluminium foils with fluorescent indicator $254 \mathrm{~nm}$ (from Merck) were used. Column chromatography was performed using SD Fine silica gel 60-120 mesh using a gradient of dichloromethane and hexane as mobile phase. High-resolution mass spectra were recorded on a Waters QTOF mass spectrometer. UVvis spectra were obtained using a Hitachi U-3900 Spectrophotometer. The infrared spectra were recorded on Agilent Technologies Model Cary 630 FTIR instruments. Mass spectra were taken with a Finnigan/Thermo Quest MAT 95XL instrument with electron impact ionization for organic compounds. Transmission electron microscopy (TEM) images were carried out on a JEOL JEMARM200FTH microscopy operated at $80 \mathrm{kV}$ with cold field emission gun (CFEG), spherical-aberration corrector, and high angle annual dark field detector. For the TEM resolution: point image resolution is $0.19 \mathrm{~nm}$, lattice image resolution is $0.10 \mathrm{~nm}$, information limit is $0.10 \mathrm{~nm}$, bright-field lattice image resolution is $0.136 \mathrm{~nm}$, and dark-field lattice image resolution is $0.08 \mathrm{~nm}$, respectively. Energy-dispersive X-ray spectroscopy (EDS) was also performed on the TEM. Raman spectra (RAMaker Raman spectrometer) with an excitation laser of $532 \mathrm{~nm}$ were also used to characterize the samples. ${ }^{1} \mathrm{H}$ NMR and ${ }^{13} \mathrm{C}$ NMR spectra were recorded on a $600 \mathrm{MHz}$ Agilent Technologies DD2 FT-NMR spectrometer. NMR shifts are reported as delta $(\delta(\mathrm{ppm})=)$ units in parts per million $(\mathrm{ppm})$ and coupling constants $(\mathrm{J})$ are reported in $\operatorname{Hertz}(\mathrm{Hz}) .1$

\subsection{Preparation of catalysts GIrNC, GCuNC, GNiNC, and GCoNC.}

(a). For preparing GIrNC, ${ }^{1,2}$ a solution prepared by dissolving $1.0 \mathrm{~g}$ of iridium(III) chloride anhydrous in $250 \mathrm{ml}$ of mixed solvent (ethyl ethanol: water $=1: 1, \mathrm{v} / \mathrm{v}$ ) was added to the $500 \mathrm{ml}$ of GO solution $(2 \mathrm{mg} / \mathrm{ml})$. The mixture solution was stirred at room temperature for $0.5 \mathrm{~h}$ and ultrasonicated for $0.5 \mathrm{~h}$, and then the mixture was refluxed for 120 hours under argon. The obtained graphene oxide-iridium complex dispersion was purified by filtration and washing with DI water and ethanol. (b). For preparing GCuNC, a solution prepared by dissolving $0.85 \mathrm{~g}$ of copper(II) sulfate pentahydrate in $250 \mathrm{ml}$ of mixed solvent (ethyl ethanol: water $=1: 1, \mathrm{v} / \mathrm{v}$ ) was added to the $500 \mathrm{ml}$ of GO solution $(2 \mathrm{mg} / \mathrm{ml})$. The mixture solution was stirred at room temperature for $0.5 \mathrm{~h}$ and ultrasonicated for $0.5 \mathrm{~h}$, and then the mixture was refluxed for 120 hours under argon. The obtained graphene oxide-copper complex dispersion was purified by filtration and washing with DI water and ethanol. (c). For preparing GNiNC, a solution prepared by dissolving $0.80 \mathrm{~g}$ of nickel(II) chloride hexahydrate in $250 \mathrm{ml}$ of mixed solvent (ethyl ethanol: water $=1: 1$, v/v) was added to the $500 \mathrm{ml}$ of GO solution $(2 \mathrm{mg} / \mathrm{ml})$. The mixture solution was stirred at room temperature for $0.5 \mathrm{~h}$ and ultrasonicated for $0.5 \mathrm{~h}$, and then the mixture was refluxed for 120 hours under argon. The obtained graphene oxide-nickel complex dispersion was purified by filtration and washing with DI water and ethanol. (d). For preparing GCoNC, a solution prepared by dissolving $0.98 \mathrm{~g}$ of cobalt(II) nitrate hexahydrate in $250 \mathrm{ml}$ of mixed solvent (ethyl ethanol: water $=1: 1, \mathrm{v} / \mathrm{v}$ ) was added to the $500 \mathrm{ml}$ of GO solution $(2 \mathrm{mg} / \mathrm{ml})$. The mixture solution was stirred at room temperature for $0.5 \mathrm{~h}$ and ultrasonicated for $0.5 \mathrm{~h}$, and then the mixture was refluxed for 120 hours under argon. The obtained graphene oxide-cobalt complex dispersion was purified by filtration and washing with DI water and ethanol.

\subsection{General Procedure for $N$-alkylation reaction.}

(a) General procedure for variety of aromatic amines and primary alcohol, $1 \mathrm{mmol}$ of amine was mixed with $2 \mathrm{mmol}$ of alcohol in the presence of catalyst GINC $(0.005 \mathrm{~g}$ for primary amines, $0.03 \mathrm{~g}$ for secondary amines and for heteroaromatic amines) in a Schlenk tube without solvent or base, and the reaction was heated to $110^{\circ} \mathrm{C}$ for $24 \mathrm{~h}$, and monitored by GCMS spectroscopy. The residue was purified by column chromatography using dichloromethane/ $\mathrm{n}$-hexane (20-100\%) or methanol/ dichloromethane (3-10\%) as eluent to afford pure products. The desired coupling products were fully characterized by ${ }^{1} \mathrm{H},{ }^{13} \mathrm{C}$ NMR, and MS spectroscopies. b) General procedure for variety of aliphatic amines and primary alcohol, $1 \mathrm{mmol}$ of amine was mixed with $2 \mathrm{mmol}$ of alcohol in the presence of catalyst GINC $(0.005 \mathrm{~g}$ for primary amines, $0.03 \mathrm{~g}$ for secondary amines) in a Schlenk tube without solvent or base, and the reaction was heated to $110^{\circ} \mathrm{C}$ for $24 \mathrm{~h}$, and monitored by GCMS spectroscopy. The residue was purified by column chromatography using dichloromethane/ $n$-hexane $(5-80 \%)$ as eluent to afford pure products. The desired coupling products were fully characterized by ${ }^{1} \mathrm{H},{ }^{13} \mathrm{C}$ NMR, and MS spectroscopies. c) General procedure for variety of amines and secondary alcohols, $1 \mathrm{mmol}$ of amine was mixed with $2 \mathrm{mmol}$ of alcohol and $0.05 \mathrm{~g}$ of catalyst GINC in a Schlenk tube without solvent or base, and the reaction was heated to $110{ }^{\circ} \mathrm{C}$ for $24 \mathrm{~h}$, and monitored by GCMS spectroscopy. The residue was purified by column 
chromatography using dichloromethane/ n-hexane (10-100\%) as eluent to afford pure products. The desired coupling products were fully characterized by ${ }^{1} \mathrm{H},{ }^{13} \mathrm{C} \mathrm{NMR}$, and MS spectroscopies

\subsection{Catalyst Reuse Studies.}

$1 \mathrm{mmol}$ aniline was mixture with $2 \mathrm{mmol}$ benzyl alcohol and $0.005 \mathrm{~g}$ catalyst GINC in a Schlenk tube. Reaction was carried out at $140{ }^{\circ} \mathrm{C}$ for $24 \mathrm{~h}$., after cooling, $5 \mathrm{ml}$ dichloromethane added to the reaction mixture and the mixture was centrifuged to separate out the catalyst, the clean supernatant was analyzed by GC-MS to identify the product composition. And then, $1 \mathrm{mmol}$ aniline and $2 \mathrm{mmol}$ benzyl alcohol was added to a Schlenk tube containing the recovered GINC for the next catalytic cycle.

\subsection{Intermolecular Cyclyzation to Synthesize Cyclizine.}

In a Schlenk tube, $1 \mathrm{mmol}$ of 2- diphenylamine was mixed with $2 \mathrm{mmol}$ of $\mathrm{N}$-methyldiethanolamine (MDEA) and $0.05 \mathrm{~g}$ of catalyst GIrNC, and the reaction was carried at $110^{\circ} \mathrm{C}$ for $48 \mathrm{~h}$ under nitrogen. Then, the reaction mixture was cooled down, the residue was purified by column chromatography using triethylamine/ $n$-hexane /dichloromethane (1:40:60, volume ratio) and triethylamine/methanol/ dichloromethane (1: 10:90, volume ratio) as eluent to afford pure products; $60 \%$ isolated yield of cyclizine was obtained. The desired products were fully characterized by ${ }^{1} \mathrm{H},{ }^{13} \mathrm{C}$ NMR, and MS spectroscopies.

\subsection{Tandem Catalysis to Synthesize Hydroxyine.}

In a Schlenk tube, $1 \mathrm{mmol}$ of aminodiphenylmethane was mixed with $2 \mathrm{mmol}$ of diethanolamine and $0.05 \mathrm{~g}$ of catalyst GIrNC, and the reaction was carried at $110^{\circ} \mathrm{C}$ for $48 \mathrm{~h}$ under nitrogen. Then, $2 \mathrm{mmol}$ of diethylene glycol was added to the above reaction mixture, the reaction was performed again at $11^{\circ} \mathrm{C}$ for $48 \mathrm{~h}$ under nitrogen. Then, the reaction mixture was cooled down, the residue was purified by column chromatography using dichloromethane/ n-hexane (50\%) and methanol/ dichloromethane (10\%) as eluent to afford pure products; $60 \%$ isolated yield of hydroxyine was obtained (calculated based on aminodiphenylmethane). The desired products were fully characterized by ${ }^{1} \mathrm{H},{ }^{13} \mathrm{C} \mathrm{NMR}$, and MS spectroscopies.

\section{Results and Discussion}

\subsection{Catalyst Preparation and Structural Characterization.}

The catalyst, iridium-graphene nanostructured catalyst (GIrNC), was prepared by the reaction of graphene oxide (GO) with iridium (III) chloride in a mixed solvent (ethoxylethanol : water $=1: 1, \mathrm{v} / \mathrm{v}$ ) at $110^{\circ} \mathrm{C}$ under argon (Scheme 1) [9], where the graphene oxide was synthesized by a modified Hummers method [10]. The infrared spectrum of graphene oxide (Figure 1a) shows that some functional groups are formed on the surface of graphene oxide [11], including hydroxyl groups of carboxylic acid and alcohol ( $\mathrm{vo-H}$ from 2800 to $\left.3700 \mathrm{~cm}^{-1}\right)$, carbonyl group $\left(v_{\mathrm{C}}=\mathrm{O}\right.$ at $\left.1730 \mathrm{~cm}^{-1}\right), \mathrm{C}=\mathrm{C}$ stretching $\left(v_{\mathrm{C}=\mathrm{C}}\right.$ at $\left.1616 \mathrm{~cm}^{-1}\right)$ and C-O stretching ( $\mathrm{VC}-\mathrm{O}$ at 1027 and $968 \mathrm{~cm}^{-1}$ ), respectively. Figure $1 \mathrm{~b}$ and 1c show the infrared spectra of samples separated from the reaction mixture during the preparation of GIrNC at 5 and 24 hours reaction time, which shows that when GO reacts with iridium(III) chloride, the $\mathrm{vO}-\mathrm{H}$ intensity of GO decreases, and the absorption of $\mathrm{VC}_{\mathrm{C}} \mathrm{O}, \mathrm{VC}=\mathrm{C}$ and $\mathrm{VC}_{\mathrm{C}} \mathrm{O}$ still exists, implying that the protons of hydroxyl groups of carboxylic acid and alcohol gradually lost, and their conjugate base, carboxylate and alkoxide ions, trapped the iridium ions to form GIrNC.

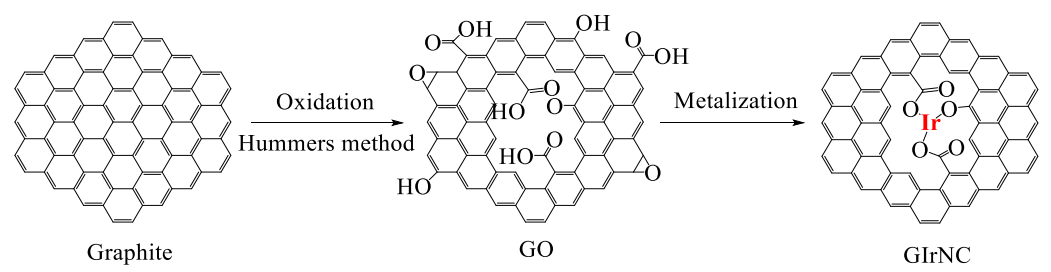

Scheme 1. Preparing Iridium/Graphene Nanostructured Catalyst 


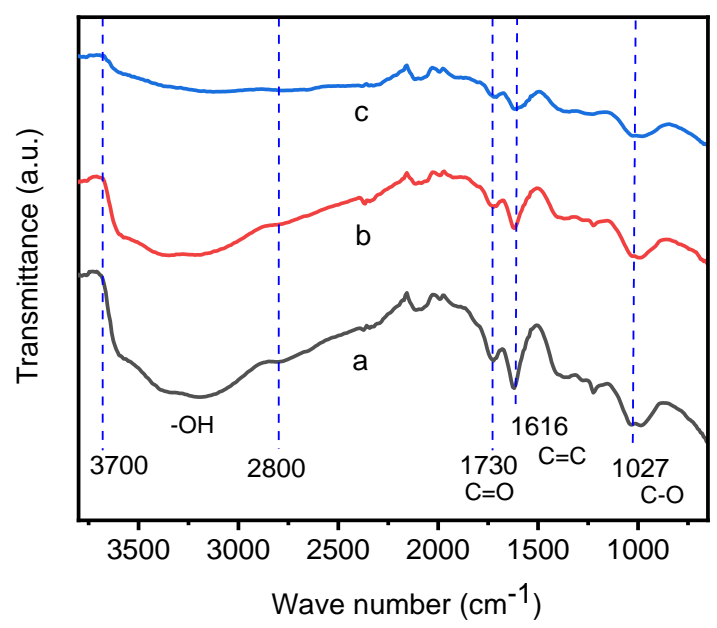

Figure 1. Infrared spectra of: (a) graphene oxide, (b) the sample separated from the reaction mixture during preparing GIrNC after reaction time of 5 hours, and (c) the sample separated from the reaction mixture during preparing GIrNC after reaction time of 24 hours.

The Ir4f XPS of GIrNC (Figure 2a) shows two characteristic peaks, the $\operatorname{Ir}_{4} \mathrm{f}_{7 / 2}$ peak centered at $61.06 \mathrm{eV}$ and the $\mathrm{Ir}_{4} \mathrm{f}_{5 / 2}$ peak centered at $64.16 \mathrm{eV}$, which are obviously higher than those of $\operatorname{Ir}^{0}$ at 60.61 , and $63.51 \mathrm{eV}$, respectively (Figure $2 \mathrm{~b}$ ), which confirms that iridium should be ionic, and bonded to GO skeleton.

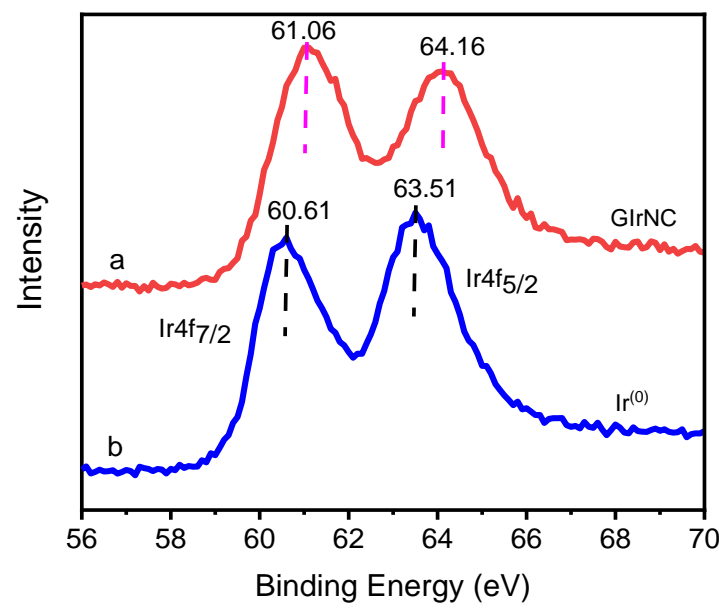

Figure 2. Ir 4f XPS spectra of (a) GIrNC, and (b) $\operatorname{Ir}^{0}$

To investigate the fine structure of GIrNC, the X-ray diffraction (XRD) pattern of GIrNC was acquired, and those of graphene, GO, and $\operatorname{Ir}^{0}$ were also obtained for comparing, which are shown in Figure 3. The characteristic XRD peak of the graphene is at around $2 \theta=26.8^{\circ}$ corresponding to the (002) of carbon (Figure 3a). The characteristic peak of the GO is at around $10.9^{\circ}$ corresponding to the (001) of GO (Figure 3b). For GIrNC (Figure 3c), a broaden peak around $10.9^{\circ}$ is observed, showing that parts of GO structure still remains in GIrNC. A peak around $2 \theta=24.2^{\circ}$ indicates that there are some graphene structures in GIrNC, which is attributed to the reconstruction of graphene structure, resulting from the decarboxylation, dehydration, and rearomatization of GO. 
Three new peaks were also observed on the pattern of GIrNC, located at around 37.7, 43.0, and $67.6^{\circ}$, respectively, which cannot be attributed to carbon and iridium elements, and should be attributed to the characteristic XRD peaks of the GIrNC. For comparison, the pattern of $\operatorname{Ir}^{0}$ is shown in Figure $3 d$, three peaks at 40.6, 47.3, and 69.3 are observed, corresponding to (111), (200) and (220) of iridium, respectively.

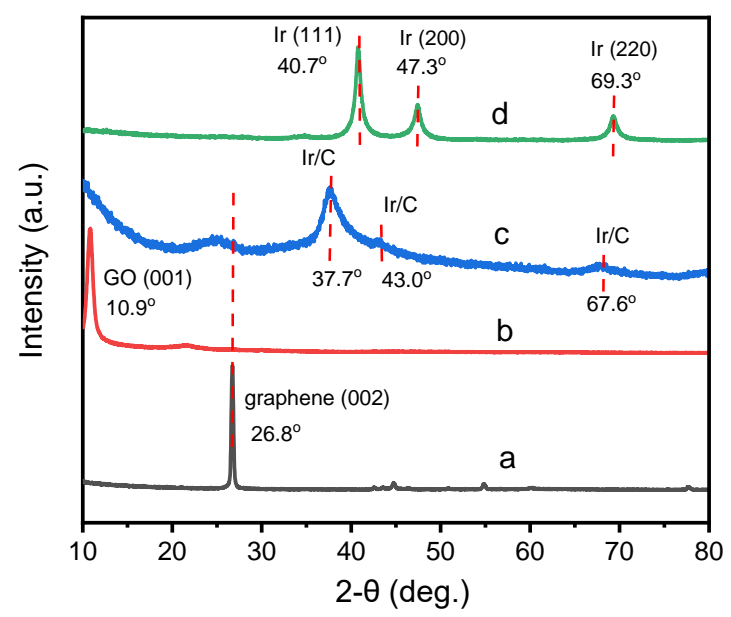

Figure 3. XRD patterns of (a) graphene, (b) GO, (c) GIrNC, and (d) $\operatorname{Ir}^{0}$ Figure 3. XRD patterns of (a) graphene, (b) GO, (c) GIrNC, and (d) $\operatorname{Ir}^{0}$

Furthermore, transmission electron microscopy (TEM) is used to study the microstructure of GIrNC. The spherical-aberration corrected field emission TEM images of GIrNC are shown in Figure 4a-c. The low magnification image (Figure 4a) shows that some substructures are formed on the surface of graphene sheet. A representative high-resolution TEM (Figure 4b) illustrates that the grain size of GIrNC ranges between 1 and $5 \mathrm{~nm}$. Figure $4 \mathrm{c}$ is an enlarged fragment taken from Figure $4 \mathrm{~b}$ (shown by the square symbol), where the hexagonal lattice of graphene and iridium structure can be observed, some of carbon atoms are replaced by iridium ions, and radii of iridium is about $1.25 \dot{A}$ belonging to the range of covalent bond of iridium. Figure $4 \mathrm{~d}-\mathrm{g}$ show the EDS element mapping of the TEM GIrNC image. Carbon atom is evenly distributed in the marked area (Figure 4e), iridium is present in the microparticle distribution area of the marked area (Figure 4f), and oxygen mainly occurs where iridium exists (Figure 4g), which means that the oxygen atom binds to iridium. 


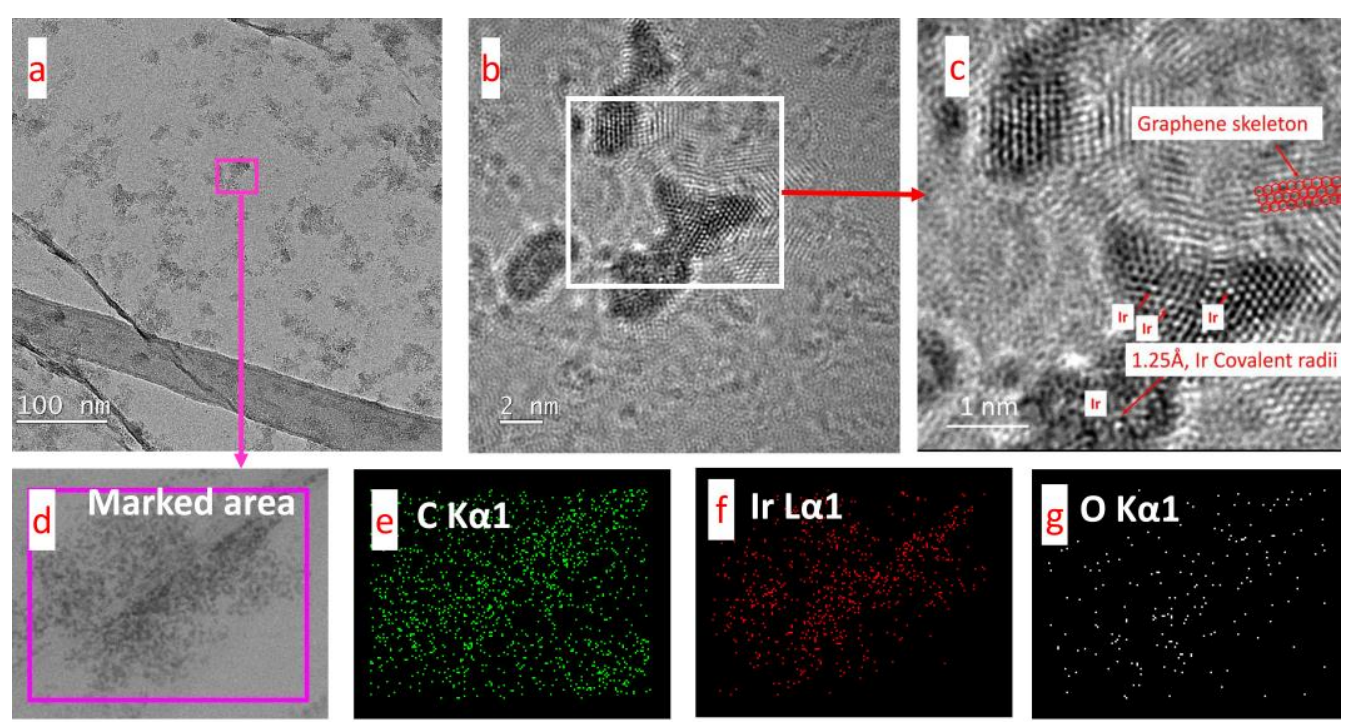

Figure 4. Spherical-aberration corrected field emission TEM images of GIrNC and EDS elemental mappings from a TEM image. (a) a low-magnification TEM image, (b). a highresolution TEM image, (c) an enlarged fragment taken from $b$ (shown by the square symbol), (d) a marked area for EDS elemental mapping, (e-g) EDS elemental mappings from the marked area.

\subsection{Initial Catalytic Studies.}

In order to optimize the catalytic conditions of the GIrNC, a series of catalytic reactions were carried out based on different catalyst loading ratios, and the effect of the catalyst loading on the selectivity of $\mathrm{N}$-alkylation was studied. The ratio of catalyst to amine is in the range from 0.0025 to $0.185(\mathrm{~g} / \mathrm{mmol})$. The reaction was carried out in a Schlenk tube at $110{ }^{\circ} \mathrm{C}$ without base and solvent for $24 \mathrm{~h}$. The composition of reaction mixture was determined by GC-MS and summarized in Figure 5. For all the reactions, aniline has been completely converted. Under high catalyst loading ratio $(0.185 \mathrm{~g} / \mathrm{mmol})$, the dialkylated product ( $\mathrm{N}, \mathrm{N}$-dibenzylaniline) is the main product $(>95 \%)$ and the monoalkylated product (N-benzylaniline) is the minor product $(\sim 4 \%)$, and trace amounts imine $(<$ $1 \%)$ was observed. In contrast, at a low loading ratio $(0.005 \mathrm{~g} / \mathrm{mmol})$, the monoalkylated product became the main product $(99 \%)$, the imine concentration was low $(1 \%)$, and no dialkylated product was detected; therefore, the selectivity of these reactions could be adjusted by adjusting the loading ratio of GIrNC. 


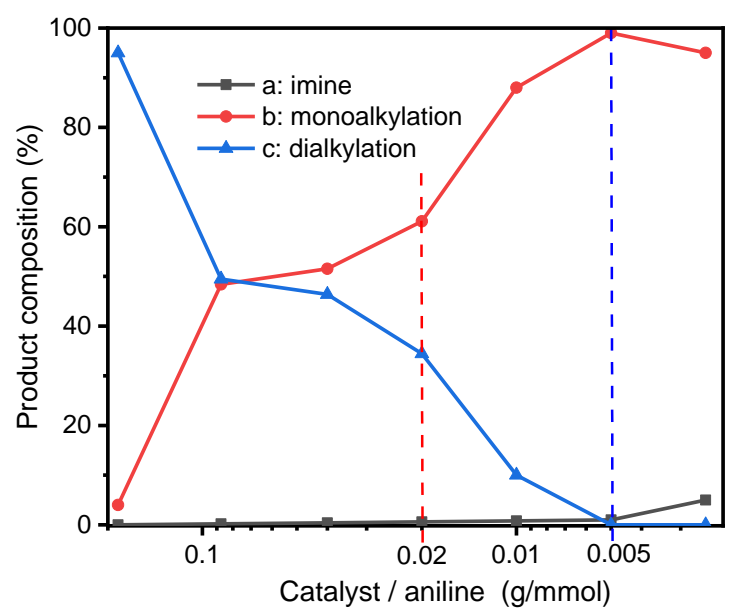

Figure 5. Composition distribution of nitrogen-containing products in the N-alkylation reaction of aniline and benzyl alcohol under various ratios of catalyst to aniline.

\subsection{Substrate Scope}

On the basis of optimized conditions, we studied the substrate scope for the catalytic hydrogen autotransfer reaction of amine and alcohol coupling (Table 21 ). In the case of aniline alkylation, with benzyl alcohol, p-anisyl alcohol and 4-chlorobenzyl alcohol as alkylating agents, the isolated yields of secondary amine products $1 \mathrm{a}, 1 \mathrm{~b}$ and $1 \mathrm{c}$ are $92 \%, 93 \%$ and $85 \%$ respectively. Substituted anilines, such as p-anisidine, 4-chloroaniline, and 5-aminoresorcinol dimethyl ether are also well alkylated by benzyl alcohol to obtain the corresponding secondary amines $1 \mathrm{~d}, 1 \mathrm{e}$, and $1 \mathrm{f}$ in high yields of $90 \%, 80 \%$ and $90 \%$, respectively. Amines with ortho electron-withdrawing group can also be alkylated smoothly, for example, 2-fluoroaniline can be effectively converted to (2-fluorophenyl)benzylamine in great yield of $1 \mathrm{~g}(87 \%)$.

In order to evaluate whether our catalyst can expand the scope for $\mathrm{N}$-alkylation of amines by aliphatic alcohols, we screened a variety of such substrates. Cheerly, aliphatic alcohols successfully alkylated amines with good selectivity and yields, for example, Using ethanol, propanol, butanol and hexanol as alkylating agents for $\mathrm{N}$-alkylation of aniline, the yields of secondary amine products $1 \mathrm{~h}, 1 \mathrm{i}, 1 \mathrm{j}$ and $1 \mathrm{k}$ are $80 \%, 68 \%, 75 \%$ and $72 \%$, respectively.

Because the formation of $\mathrm{C}-\mathrm{N}$ bonds between nitrogen and secondary carbon is an important step in the construction of some natural products or drugs, for example, bucrine, cinnarizine, hydroxyzine and ofloxacin, we tested the alkylation of amine by using secondary aliphatic alcohols as alkylating reagent to construct this kind of bonding. To our delight, both aromatic and aliphatic amines can be coupled with secondary aliphatic alcohols. Most of those reactions have a high conversion with good to excellent yield. For example, 4-methoxyanline is alkylated with secondary benzylic alcohol (1-phenylethanol), the conversion rate is $90 \%$, and the corresponding product 11 is obtained in yield of $79 \%$. Secondary aliphatic alcohols also successfully alkylated aromatic amines, for example, aniline and 4-methoxyanline were smoothly alkylated by iso-propanol to obtain the corresponding products $1 \mathrm{~m}$ and $1 \mathrm{n}$ with yields of $90 \%$ and $92 \%$, respectively.

We also found excellent scope and functional group tolerance. For example, the coupling yields of benzyl alcohol with aminopyridine, aminopyrimidine, and 2- 
aminobenzimidazole (products 1o-1q) are 95\%, 56\%, and 85\%, respectively. The synthesis of 1o-1q shows efficient access to building blocks used in antihistamine and antitumor drugs, including tripelennaine, mepyramine, chloropyramine, and MSX-122.

Table 1. GIrNC-Catalyzed N-Alkylation of Amines Using Alcoholsa

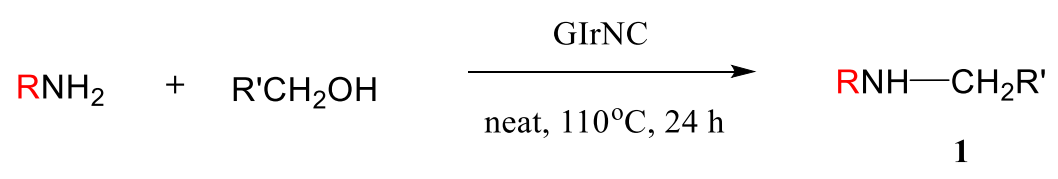

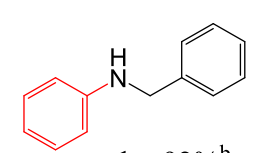

1a, $92 \%$ b<smiles>COc1ccc(NCc2ccccc2)cc1</smiles>

1d, $90 \%$

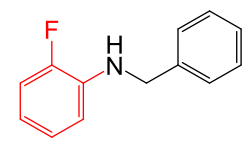

1g, $87 \%$

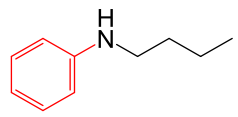

1j, 75\%

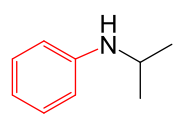

1m, $90 \%$

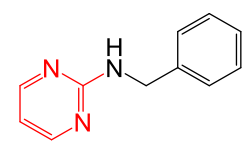

1p, 56\%<smiles>COc1ccc(CNc2ccccc2)cc1</smiles>

1b, $93 \%$<smiles>Clc1ccc(CNc2ccccc2)cc1</smiles>

1c, $85 \%$<smiles>Clc1ccc(NCc2ccccc2)cc1</smiles>

1e, $80 \%$<smiles>COc1cc(NCc2ccccc2)cc(OC)c1</smiles><smiles>CCNc1ccccc1</smiles>

1h, $80 \%$<smiles>CCCCCCNc1ccccc1</smiles>

$1 \mathrm{k}, 72 \%$<smiles>COc1ccc(NC(C)C)cc1</smiles>

1n, $92 \%$<smiles>CCCNc1ccccc1</smiles>

1i, $68 \%$<smiles>COc1ccc(NC(C)c2ccccc2)cc1</smiles>

11, $79 \%$<smiles>c1ccc(CNc2ccccn2)cc1</smiles>

$1095 \%$

Amines $(1 \mathrm{mmol})$, alcohols $(2 \mathrm{mmol})$, catalyst $(0.005 \mathrm{~g})$, without base and solvent, and reaction was carried out at $110{ }^{\circ} \mathrm{C}$ for $24 \mathrm{~h} .{ }^{\mathrm{b}}$ isolated yields.

Another feature of this reaction is that it is possible to use two different alcohols to achieve one-pot unsymmetrical N,N-dialkylation of amines with significant selectivity. For example, aniline was reacted with one equivalent of benzyl alcohol to provide monoalkylation. Subsequently, a different primary alcohol was introduced, which provides the unsymmetrical N,N-dialkylated products 2a, 2b, and 2c in high isolated yields of $82 \%, 80 \%$ and $86 \%$, respectively. (Scheme 2). 
<smiles>Nc1ccccc1CO</smiles><smiles></smiles>

Scheme 2. GIrNC-Catalyzed Unsymmetrical N,N-Dialkylation of Aniline Using Alcohols.

Next, we tested the intermolecular cyclization through the reaction of amine and diol. Aniline, 4-chloroaniline and 4-methoxyaniline react with 1,4-butanediol to form a cyclized five-membered cyclic amines $3 a, 3 b$, and $3 c$ in $80 \%, 85 \%$, and $89 \%$ yields, respectively (Table 2). The reaction of 1,5- pentanediol with different amines gives six-membered cyclized products in good yields (3d-3e). Interestingly, by using diethanolamine or N-substituted diethanolamine, piperazine derivatives were obtained (3g-3i). Among them, pyridylpiperazine derivatives $(3 \mathrm{~g})$ are known to be effective and selective $\alpha 2$-adrenergic receptor antagonists, and benzylpiperazine (BZP) (3h) is a recreational drug with euphoric properties. The phenylpiperazine derivative (3i) is characterized by the phenyl group attached to the piperazine ring. Many phenylpiperazine derivatives are medicines, such as Antrafenine, Bifeprunox, Ciprofloxacin, Dropropizine. and Elopiprazole.

Table 2 GIrNC-Catalyzed Intermolecular Cyclization of Amins Using Diol ${ }^{a}$

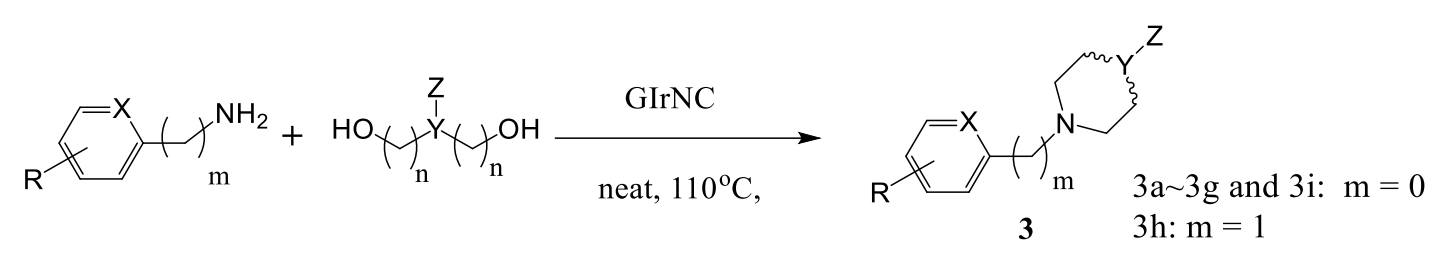

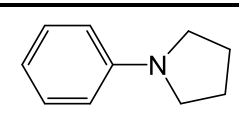

3a, $80 \%$ b

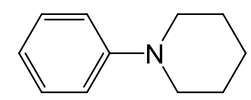

3d, $75 \%$<smiles>CN1CCN(c2ccccn2)CC1</smiles>

3g, $70 \%$<smiles>Clc1ccc(N2CCCC2)cc1</smiles>

$3 \mathbf{b}, 85 \%$<smiles>COc1ccc(N2CCCCC2)cc1</smiles>

3e, $78 \%$<smiles>c1ccc(CN2CCNCC2)cc1</smiles>

3h, $90 \%$

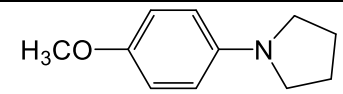

3c, $89 \%$<smiles>c1ccc(N2CCCCC2)nc1</smiles>

3f, $70 \%$

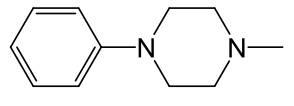

3i, $75 \%$

Amines $(1 \mathrm{mmol})$, alcohols $(2 \mathrm{mmol})$, catalyst $(0.005 \mathrm{~g})$, without base and solvent, and reaction was carried out at $110{ }^{\circ} \mathrm{C}$ for $24 \mathrm{~h}$. $\quad{ }^{\mathrm{b}}$ isolated yields. 
The above results indicate that the GIrNC has good catalytic activity and C-N bond formation selectivity. The following two examples illustrate the advantages of this catalyst in organic synthesis

\subsection{Synthetic Applications.}

First, cyclizine was successfully synthesized in a one-step reaction through intermolecular cyclization promoted by GIrNC catalysis. Cyclizine has been included in the World Health Organization Essential Medicines List for the treatment and prevention of nausea, vomiting and dizziness caused by motion sickness or dizziness [12]. Scheme 3a shows three previous reports used to prepare cyclizine. Both 3aI[13] and 3aII [14] routes require at least four steps, with total yields of $30 \%$ and $44 \%$, respectively. Many harmful and expensive chemicals (such as formaldehyde, alkyl halide, and reducing agents) must be used, and toxic and ecologically unfavorable substances (such as hydrogen halides and solvents) are released into the environment. Recently, a more environmentally friendly method using a ruthenium complex catalyst has been found (3aIII) [15], but the yield is very low (about 10\%).

Our case (Scheme 3b) uses an intermolecular cyclization reaction to prepare cyclizine through onestep catalysis. In the reactor, N-methyldiethanolamine (MDEA) was mixed with diphenylamine and the catalyst GIrNC, and the reaction was carried out at $110^{\circ} \mathrm{C}$ under nitrogen. After 24 hours, the reaction mixture was cooled, the catalyst was filtered off, and the filtrate was purified by column chromatography. The isolated yield of cyclizine is $60 \%$, which is a very good yield compared with known methods.

(a)
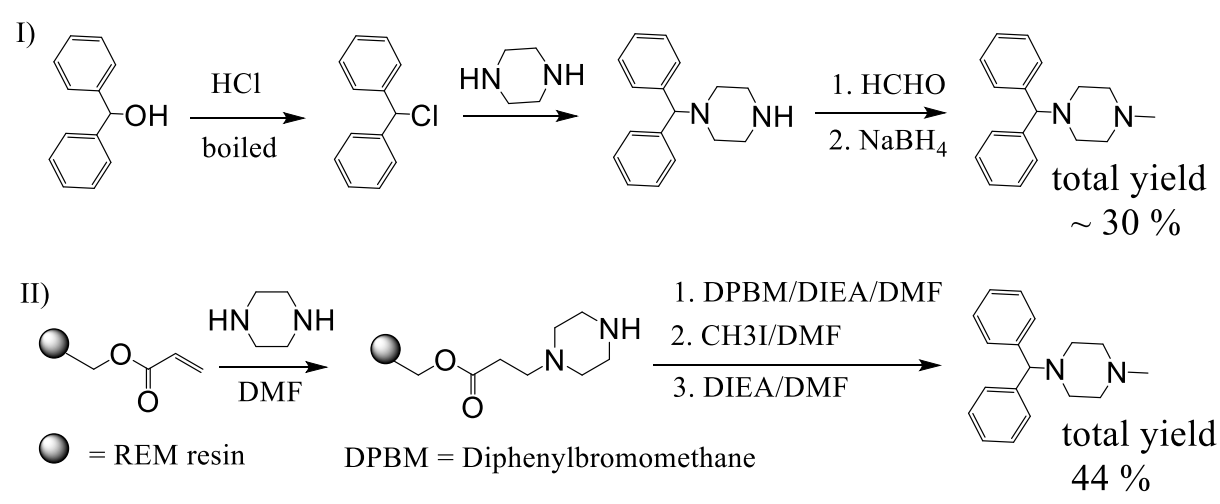

III)<smiles>OCCN(CO)CO</smiles><smiles>NC1CCCCC1</smiles>

[ $\mathrm{Ru}] / \mathrm{NaOH}$

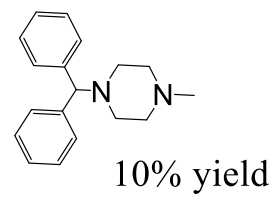

(b)<smiles>CN(CO)CCO</smiles><smiles>NC1(c2ccccc2)CCCCC1</smiles>
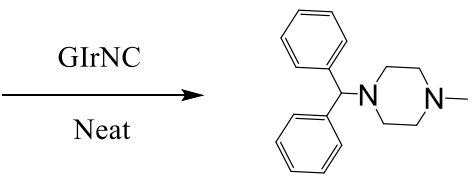

$60 \%$ yield

Scheme 3. Synthesis of Cyclizine: (a) Previous Reports, (b) Our Case

Secondly, under the catalysis of GIrNC, hydroxyine was also successfully obtained through a tandem reaction involving intermolecular cyclization and $\mathrm{N}$-alkylation. Hydroxyine has some $\mathrm{C}-\mathrm{N}$ 
bonds, which are usually established through more complicated processes in traditional methods. Hydroxyzine is a first-generation antihistamine that belongs to the diphenylmethane and piperazine classes. Because it can bind to certain receptors in the brain, it is used as a powerful anti-anxiety drug and a mild anti-obsessive-compulsive disorder drug to treat mental anxiety and tension. Due to its antihistamine effect, it can also treat severe itching and hyperalgesia, and can even be used as a drug to relieve symptoms of opioid withdrawal; in addition, hydroxyzine derivatives are also research objects for the treatment of viral infections[16]. So far, there are many methods for producing hydroxyine, but most of them are stoichiometric reactions through a long production process. Scheme $4 \mathrm{a}$ is a patented process for industrial production of hydroxyzine, which includes at least three main steps. It requires the use of a variety of materials, including solvents, acids, bases, organic halides and other toxic chemicals. In addition, the harmful by-products produced during the manufacturing process require special equipment to handle, and multi-step synthesis pathways and side reactions lead to increased product costs[17].

Our case (Scheme $4 \mathrm{~b}$ ) provides a method for the preparation of hydroxyine through a onepot reaction in tandem catalysis. In a reactor, aminodiphenylmethane was mixed with diethanolamine (DEA) and the catalyst GIrNC, and the reaction was carried out at $110^{\circ} \mathrm{C}$ under a nitrogen atmosphere for 24 hours. Then, diethylene glycol (DEG) was added to the above reaction mixture, and reacted again at $110^{\circ} \mathrm{C}$ for 24 hours under nitrogen. Then, the reaction mixture was cooled, the catalyst was filtered off, and the filtrate was purified by column chromatography. The isolated yield of hydroxyine obtained is $55 \%$, which is a moderate yield for one-pot synthesis. The only by-product is water, no solvent, alkali or other additives are needed, and the catalyst can be recycled.

(a)

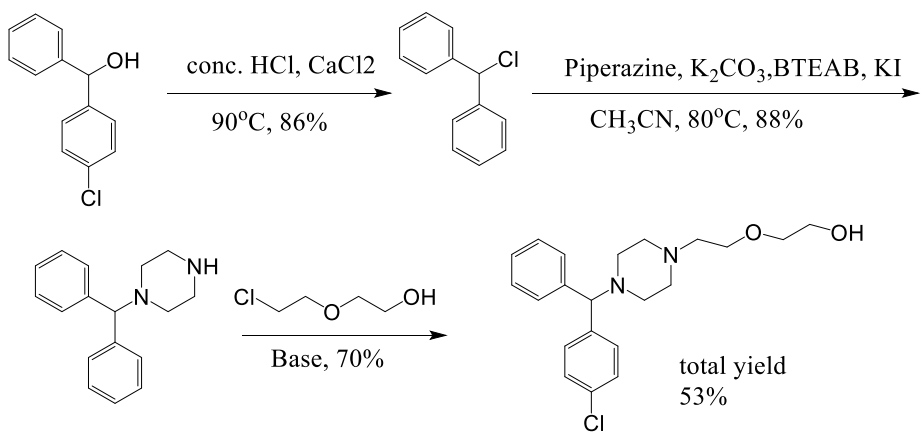

(b)

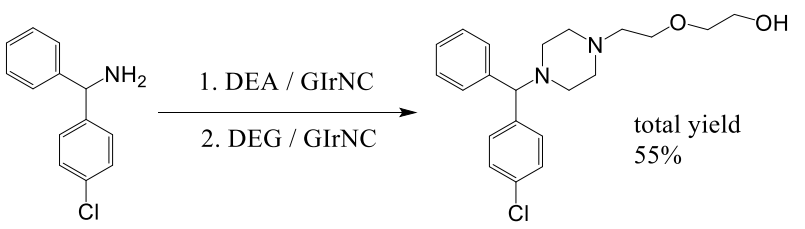

Scheme 4. Synthesis of Hydroxyine: (a) Previous Report, (b) Our Case

\subsection{Reliability of GIrNC in Catalytic Cycle.}

Ideally, heterogeneous catalysts can be used in a continuous production process, and the product can easily be separated from the reaction mixtures. Therefore, we studied the catalyst reuse of GIrNC for the N-alkylation of aniline in five catalytic cycles without a regeneration step to evaluate the activity and stability of GIrNC in the long-term catalytic process. For each cycle, $1 \mathrm{mmol}$ amine was mixture with $2 \mathrm{mmol}$ alcohol and $0.005 \mathrm{~g}$ catalyst GIrNC. Reaction was carried out at $110{ }^{\circ} \mathrm{C}$ for $24 \mathrm{~h}$, the recycled catalyst was isolated by centrifuged, and used for the next round. The yield of N-benzylaniline in each catalytic cycle is shown in Figure 6. The yield of the first cycle is $95.9 \%$. The yield of second cycle is $89.3 \%$, decreased by $6.6 \%$. Fortunately, after the second cycle, the yields remained between $89.4 \%$ and $89.7 \%$, and the yield of the fifth cycle is $89.5 \%$, indicating that the catalyst is quite stable under the reaction conditions. Because the 
catalytic ability of the catalyst remains almost unchanged after the second cycle, it can be seen that the catalyst will not encounter the problem of deactivation.

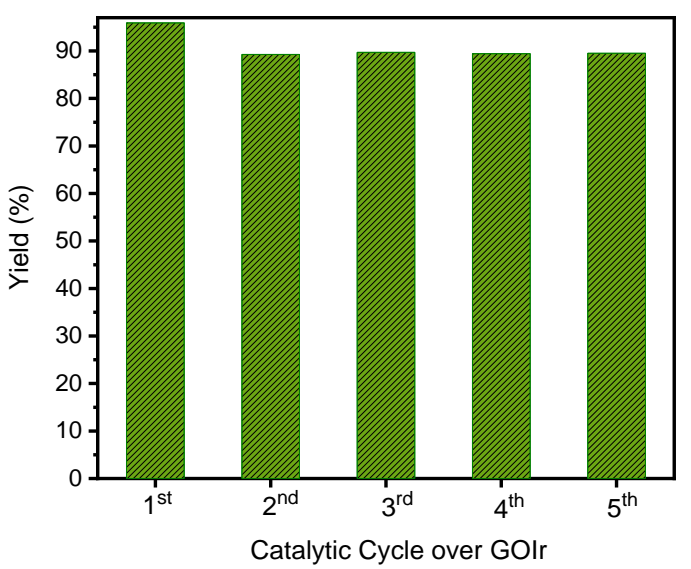

Figure 6. Production yield of each catalytic cycle for the N-alkylation of aniline reacted with benzyl alcohol to produce N-benzylaniline.

To check the structural stability of catalyst during catalysis, Raman spectra of original and reused catalysts were acquired for inspecting the structural characteristics of catalyst. The Raman spectrum of original catalyst shows a broad D band peak (the vibration of carbon atoms with $\mathrm{sp}^{3} \mathrm{elec}^{-}$ tronic configuration) at $1343 \mathrm{~cm}^{-1}$ and a $\mathrm{G}$ band peak (in-plane vibration of $\mathrm{sp}^{2}$ - bonded carbon atoms) at $1583 \mathrm{~cm}^{-1}$ (Figure 7). During five catalytic cycles, the location of D band and $\mathrm{G}$ band peaks of the catalyst remain unchanged. The integrated peak area ratio of the $\mathrm{D}$ to $\mathrm{G}$ band $\left(\mathrm{I}_{\mathrm{D}} / \mathrm{I}_{\mathrm{G}}\right)$ of the original catalyst is 1.15 , and the $\mathrm{I}_{\mathrm{D}} / \mathrm{I}_{\mathrm{G}}$ value of catalyst after one run is 1.08 , showing the ID/IG value changes slightly after one run. The $\mathrm{I}_{\mathrm{D}} / \mathrm{I}_{\mathrm{G}}$ value of catalyst after the $3^{\text {rd }}$ run is the same as the catalyst after the $5^{\text {th }}$ run (1.07) and there is no significant difference between the catalyst after the first run. The changes in the full width at half maximum (FWHM) of the D band of original catalyst, and the catalysts after the $1^{\text {st }}, 3^{\text {rd }}$, and $5^{\text {th }}$ runs are $93,93,92$ and $92 \mathrm{~cm}^{-1}$, respectively, showing that there is no significant change in the FWHM of the D band during the catalysis process. Through the Raman spectroscopy analysis of the original catalyst and the reused catalyst, we can see that although the catalyst has a slight structural change after the first run, the structural characteristics of the catalyst remain almost unchanged since then.

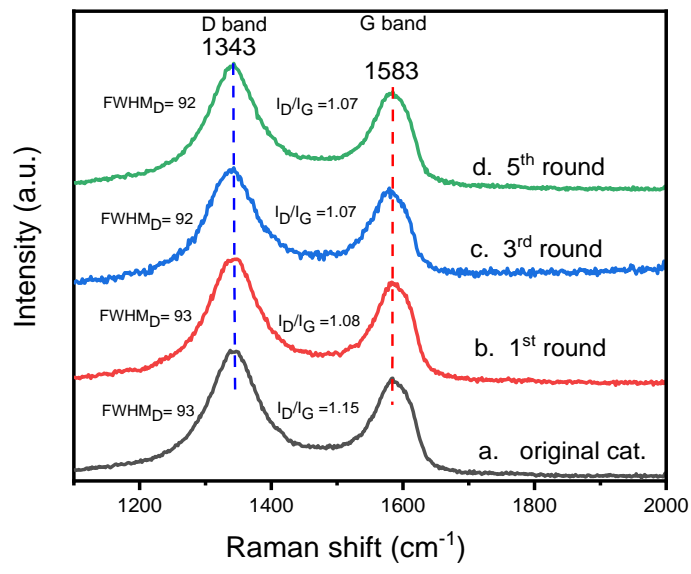

Figure 7. The Raman spectra of original and reused catalysts.

The Ir4f XPS of original catalyst shows two characteristic peaks, the $\operatorname{Ir}_{4} \mathrm{f}_{7 / 2}$ peak is centered at 61.06 $\mathrm{eV}$ and the $\mathrm{Ir}_{4} \mathrm{f}_{5 / 2}$ peak is centered at $64.16 \mathrm{eV}$ (Figure 8a). For the reused catalyst (Figure 8b-d), the position, relative intensity and peak shape of the $\operatorname{Ir}_{4} \mathrm{f}_{7 / 2}$ and $\operatorname{Ir}_{4} \mathrm{f}_{5 / 2}$ peaks are the same as the 
original catalyst, showing the oxidation state of iridium remains unchanged, and the bonding mode of iridium on graphene is stable. We also checked the atomic percentage of iridium in the catalyst. The newly prepared catalyst has an iridium atomic ratio of $3.2 \%$. The atomic ratio of iridium in the catalysts of the first, third and fifth cycles are $2.9 \% .2 .8 \%$ and $2.8 \%$ respectively, which can explain why the yield of $\mathrm{N}$-alkylation products decreased by $6.6 \%$ from the first cycle to the second cycle, but remained almost unchanged after the second cycle. We can infer that GIrNC is stable, but a few iridium atoms are loosely bound and may leave the catalyst surface in the first run; however, most of the catalytically active sites are firmly fixed on the graphene surface and remain active for a long time.

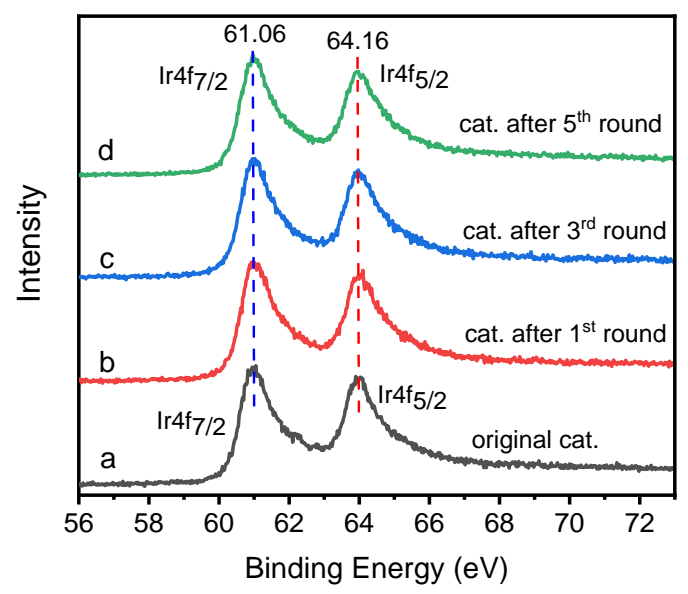

Figure 8. Ir 4f XPS spectra of catalyst of original catalyst, and the reused catalysts after $1^{\text {st }}, 3^{\text {rd }}$, and $5^{\text {th }}$ run, respectively.

\section{Conclusions}

In conclusion, we have successfully demonstrated an unprecedented iridium/graphene nanostructured catalyst for the effective and direct coupling of amines and alcohols to form $\mathrm{CN}$ bonds. The reactions can be carried out under neat conditions, without preactivation steps, and without solvents, alkalis and other additives. Both aromatic and aliphatic amines can be alkylated, and both aromatic and aliphatic alcohols can be used as alkylating agents with excellent selectivity and yield. The asymmetric N,N-dialkylation of amines using alcohols is achieved in a one-pot synthesis. Advantageously, various functional groups such as halides, alkoxy, hydroxyl, and heteroaromatic groups can be tolerated in this catalytic protocol. Interestingly, the use of diols resulted in the formation of five- and six-membered cyclic amines and piperazine derivatives, which are analogous to various drugs and biologically active molecules. This catalytic method also proved its feasibility in drug synthesis, for example, under the catalysis of GIrNC, cyclizine was prepared through a one-step reaction of intermolecular cyclyzation, and hydroxyine was obtained through a tandem reaction. This synthetic strategy can inspire the development of new $\mathrm{C}-\mathrm{N}$ bond formation reactions and sustainable transformations.

Supplementary Materials: The following are available online at www.mdpi.com/xxx/s1, Experimental data.

Author Contributions: Writing - original draft preparation, T.R.Chen.; the preparation of the catalysts, Y.T.Chen; catalytic studies, T.R.Chen, Y.T.Chen, Y.H. Lin, and H.C. Wang; All authors have read and agreed to the published version of the manuscript. 
Funding This work was supported by the Ministry of Science and Technology (MOST 109-2622-M-153001-CC3).

Data Availability Statement: The data presented in this study are available on request from the corresponding author

Acknowledgments: The authors would like to thank Ms. Yin-Mei Chang (Instrument Center, NTHU) for TEM analysis and thank the Instrument Center of National Chung Hsing University for help with measurements of Nuclear Magnetic Resonance and LC-MS/MS (MOST 108-2731 -M-005 -001).

Conflicts of Interest: The authors declare no conflict of interest.

\section{References}

1. Powell, D. A.; Ramsden, P.D.; Batey, R. A. Phase-Transfer-Catalyzed Alkylation of Guanidines by Alkyl Halides under Biphasic Conditions: A Convenient Protocol for the Synthesis of Highly Functionalized Guanidines. J. Org. Chem. 2003, 68, 2300-2309

2. Mirabdolbaghi, R.; Dudding, T. Expanding the Forefront of Strong Organic Brønsted Acids: Proton-Catalyzed Hydroamination of Unactivated Alkenes and Activation of Au(I) for Alkyne Hydroamination. Org. Lett. 2015, 17, 1930-1933.

3. Lee, D.-H.; Taher, A.; Hossain, S.; Jin,M.-J. An Efficient and General Method for the Heck and Buchwald_Hartwig Coupling Reactions of Aryl Chlorides. Org. Lett., 2011, 13, 5540-5543.

4. Zhao, X.; Y She,; K Fang,.; Li, G. CuCl-Catalyzed Ullmann-Type C-N Cross-Coupling Reaction of Carbazoles and 2-Bromopyridine Derivatives. J. Org. Chem. 2017, 82, 1024-1033.

5. Thiyagarajan, S.; Gunanathan, C. Direct Catalytic Symmetrical, Unsymmetrical N,N-Dialkylation and Cyclization of Acylhydrazides Using Alcohols. Org. Lett. 2020, 22, 6617-6622.

6. (a) Balaraman, E.; Srimani, D.; Diskin-Posner, Y.; Milstein, D. Direct Synthesis of Secondary Amines From Alcohols and Ammonia Catalyzed by a Ruthenium Pincer Complex, Catal. Lett. 2015, 145, 139-144. (b) Dang, T. T.; Ramalingam, B.; Seayad, A. M. Efficient Ruthenium-Catalyzed N-Methylation of Amines Using Methanol, ACS Catal. 2015, 5, 4082-4088. (c) Broomfield, L. M.; Wu, Y.; Martin, E.; Shafir, A. Phosphino-amine (PN) Ligands for Rapid Catalyst Discovery in Ruthenium-Catalyzed Hydrogen-Borrowing Alkylation of Anilines: A Proof of Principle, Adv. Synth. Catal. 2015, 357, 3538-3548. (d) Marichev K.O.; Takacs, J. M. Ruthenium-Catalyzed Amination of Secondary Alcohols Using Borrowing Hydrogen Methodology, ACS Catal. 2016, 6, 2205-2210.

7. (a) Wang, D.; Zhao, K.; Yu, X.; Miao, H.; Ding, Y. Iridium-CNP complex catalyzed cross-coupling of primary alcohols and secondary alcohols by a borrowing hydrogen strategy, RSC Adv. 2014, 4, 42924-42929. (b) Kawahara, R.; Fujita, K.; Yamaguchi, R. N-Alkylation of Amines with Alcohols Catalyzed by a Water-Soluble Cp*Iridium Complex: An Efficient Method for the Synthesis of Amines in Aqueous Media, Adv. Synth. Catal. 2011, 353, 1161-1168. (c) Michlik, S.; Hille, T.; Kempe, R. The Iridium-Catalyzed Synthesis of Symmetrically and Unsymmetrically Alkylated Diamines under Mild Reaction Conditions, Adv. Synth. Catal. 2012, 354, 847-862.

8. Yan,T.; Feringa, B.L.; Barta, K. Benzylamines via Iron-Catalyzed Direct Amination of Benzyl Alcohols, ACS Catal. 2016, 6, $381-388$.

9. (a) Chen, T.-R.; Wang, Y.-X.; Lee, W.-J.; Chen, K. H.-C.; Chen J-D. A reduced graphene oxide-supported iridium nanocatalyst for selective transformation of alcohols into carbonyl compounds via a green process, Nanotechnology 2020, 31, 285705. (b) Chen, T.-R.; Lin, Y.-S.; Wang, Y.-X.; Lee, W.-J.; Chen, K. H.-C.; Chen J-D. Graphene oxide-iridium nanocatalyst for the transformation of benzylic alcohols into carbonyl compounds, RSC Adv., 2020, 10, 4436-4445.

10. (a) Zhang, Q.; Zheng, H.; Geng, Z.; Jiang, S.; Ge, J.; Fan, K.; Duan, S.; Chen, Y.; Wang, X.; Luo, Y. The Realistic Domain Structure of AsSynthesized Graphene Oxide from Ultrafast Spectroscopy, J. Am. Chem. Soc. 2013, 13, 12468-12469. (b) Zhang, H.; Bhat, V. V.; Gallego, N. C.; Contescu, C. I. Thermal Treatment Effects on Charge Storage Performance of Graphene-Based Materials for Supercapacitors, ACS Appl. Mater. Interfaces 2012, 4, 3239-3243.

11. (a) Shen, J.; Hu, Y.; Shi, M.; Lu, X.; Qin, C.; Li, C.; Ye, M. Fast and Facile Preparation of Graphene Oxide and Reduced Graphene Oxide Nanoplatelets, Chem. Mater. 2009, 21, 3514-3520. (b) Chen, X.; Chen, B. Macroscopic and Spectroscopic Investigations of the Adsorption of Nitroaromatic Compounds on Graphene Oxide, Reduced Graphene Oxide, and Graphene Nanosheets, Environ. Sci. Technol. 2015, 49, 6181-6189.

12. Clubiey, M.; Henson, T.; Peck, A. W.; Riddington, C. Effects of caffeine and cyclizine alone and in combination on human performance and subjective ratings. Br. J. Clin. Pharmacol. 1977, 4, 652.

13. Afanasyev, O. I.; Kuchuk, E.; Usanov, D. L.; Chusov, D. Reductive Amination in the Synthesis of Pharmaceuticals. Chem. Rev. 2019, 119, 11857-11911.

14. Brown, A. R.; Rees, D. C.; Rankovic, Z.; Morphy, J. R. Synthesis of Tertiary Amines Using a Polystyrene (REM) Resin. J. Am. Chem. Soc. 1997, 119, 3288-3295.

15. Abbenhuis, R. A. T. M.; Boersma, J.; van Koten, G. Ruthenium-Complex-Catalyzed N-(Cyclo)alkylation of Aromatic Amines with Diols. Selective Synthesis of $N$ - $(\ddot{o}$-Hydroxyalkyl)anilines of Type $\mathrm{PhNH}(\mathrm{CH} 2) n \mathrm{OH}$ and of Some Bioactive Arylpiperazines. J. Org. Chem. 1998, 63, 4282-4290.

16. (a) He, S.; Xiao, J.; Dulcey, A. E.; Lin, B.; Rolt, A.; Hu, Z.; Hu, X.; Wang, A. Q.; Xu, X;. Southall, N.; Ferrer, M.; Zheng, W.; Liang, T. J.; Marugan, J. J. Discovery, Optimization, and Characterization of Novel Chlorcyclizine Derivatives for the Treatment of Hepatitis C Virus Infection. J. Med. Chem. 2016, 59, 841-853. (b) Baker, J. D.; Uhrich, R. L.; Strovas, T. J.; Saxton, A. D.; Kraemer, B. C. Targeting Pathological Tau by Small Molecule Inhibition of the Poly(A):MSUT2 RNA-Protein Interaction ACS Chem. Neurosci. 2020, 11, $2277-2285$.

17. Morren, H.; Brussels, F. Piperazine ethers and their method of preparation. United States Patent 2,899,436 Patented Aug. $11,1959$. 